\title{
REPRESENTAÇÕES LITERÁRIAS DA IDENTIDADE E DA ALTERIDADE EM TORNO DE ESTEREÓTIPOS DA CEGUEIRA
}

RICARDO SOBREIRA*

\section{RESUMO}

No presente estudo, analisamos representações ficcionais de embates identitários entre o eu e o outro em uma narrativa literária contemporânea. Essas configurações das identidades e das diferenças são analisadas, com base em teorias interdisciplinares, no conto minimalista "Catedral" (1983), do autor norte-americano Raymond Carver. O texto literário problematiza a estereotipagem de alteridades por conta de raça, de gênero e de deficiências físicas. Nesse duelo de performances masculinas, o eu-narrador do conto vêse obrigado a negociar simbolicamente suas próprias fobias e ansiedades em relação às diferenças.

PalaVRas-Chave: identidade, alteridade, Raymond Carver, sujeito, pósmodernidade.

O presente artigo busca investigar, com base em um arcabouço teórico interdisciplinar, como a arte literária pode problematizar questões vinculadas à constituição identitária do sujeito ficcional. Essas indagações dizem respeito aos embates sugeridos narrativamente entre o eu e o "outro", compreendidos como figurações, nunca estanques, de identidades e de alteridades. Optamos, neste estudo, por selecionar um conto literário - "Catedral" (1983), do escritor norte-americano Raymond Carver - como foco de análise devido ao fato de ele instigar um debate, travado ao longo de vários estudos, de representações identitárias do eu e do "outro".

Este artigo está organizado em três partes distintas. Com o intuito de dissipar possíveis ambiguidades terminológicas, dedicamos a primeira seção, denominada "Percorrendo os labirínticos caminhos da identidade e da alteridade", a um breve cotejo dos principais conceitos teóricos mobilizados em nossa abordagem do texto literário,

\footnotetext{
* Mestre e doutor em Letras pela Universidade Estadual Paulista "Júlio de Mesquita Filho" (UNESP), São Paulo, Brasil. E-mail: ricardosobreira@hotmail.com.
} 
nomeadamente as noções de sujeito, de identidade e de alteridade sob a perspectiva dos estudos da chamada pós-modernidade (cf. LYOTARD, 1988; JAMESON, 1991; BYERS, 2011; HARVEY, 2012). Na segunda seção, intitulada "Pode porventura um cego guiar outro cego?", discutimos brevemente a construção de masculinidades precárias em contos de Carver e, em seguida, analisamos as questões de alteridades e de identidades implicadas na narrativa "Catedral", com base nos eixos estabelecidos na primeira parte. Nas "Considerações finais", retomamos alguns pontos principais da discussão e promovemos uma breve reflexão em torno das implicações religiosas e identitárias contidas na simbologia da cegueira.

\section{PERCORRENDO OS LABIRÍNTICOS CAMINHOS DA IDENTIDADE E DA} ALTERIDADE

A ideia de sujeito é constituída sobretudo a partir de teorias pósmodernas, cuja orientação dá-se no sentido da contestação de hipóteses - que eram defendidas durante o período moderno - referentes à relativa coerência social e lógica causal atribuída ao sujeito humano. Conforme observam Steven Best e Douglas Kellner (1991), "a teoria pós-moderna abandona o sujeito racional e unificado postulado por grande parte das teorias modernas em favor de uma forma de subjetividade fragmentada e linguisticamente descentrada" (p. 4-5). ${ }^{1} \mathrm{O}$ atual estágio do capitalismo, definido por teorias econômicas como sendo uma manifestação tardia, é caracterizado, especialmente em nações altamente desenvolvidas, pela ênfase no hiperconsumismo e na cultura multimidiática (JAMESON, 1991) e, por esses motivos, tem suscitado a fragmentação da ideia tradicional de sujeito, que passa a ser interpretado como um ponto de convergência e de divergência simultâneas de identidades múltiplas, híbridas e, muitas vezes, contraditórias coexistentes no âmbito da subjetividade do indivíduo (HALL, 1992, p. 277). Este, por sua vez, não pode mais ser considerado único, acabado ou estável, mas como um campo de ações performáticas, marcado pela multiplicidade, pluralidade, fragmentação e indeterminação (BEST; KELLNER, 1991, p. 4). Nesse mesmo sentido, Carlos Rincón (1995), com base em aspectos socioculturais do capitalismo tardio, propõe a seguinte 
distinção entre a visão clássica de sujeito e as formulações desse novo sujeito pós-moderno:

O sujeito reflexivo, centrado e unitário das Kritiken de Kant e das abstrações de Max Weber teria sido substituído por um mutável sujeito descentrado, difuso e fragmentário que se move em um espaço que já não está socialmente estruturado de uma maneira binária. Com isso, a questão da constituição de identidades também foi rediscutida (RINCÓN, 1995, p. 111). ${ }^{2}$

Por sua vez, o conceito de identidade pode ser constituído como um conjunto de características e de atributos que identificam um indivíduo ou uma coletividade como uma espécie de entidade específica (ZOUYANÉ, 2014). A percepção dessa identificação, pelo próprio eu e pelo outro, é feita com base em uma realidade dinâmica e em permanentes construções e negociações simbólicas. Cabe salientar que essa identidade - em oposição às tradicionais formas identitárias - não são centradas, nem monádicas ou fixas, como observa Zygmunt Bauman:

A eventual solidez que [as identidades] podem ter quando contempladas de dentro da própria experiência biográfica parece frágil, vulnerável e constantemente dilacerada por forças que expõem sua fluidez e por contracorrentes que ameaçam fazê-la em pedaços e desmanchar qualquer forma que possa ter adquirido (BAUMAN, 2001, p.98).

Tomemos como exemplo as identidades de gênero no contexto contemporâneo. Muito se tem discutido a respeito das crises envolvendo o papel das mulheres e das chamadas diversidades sexuais. Contudo, mesmo as masculinidades heterossexuais dominantes, como sugere Bauman, têm sido fragilizadas e "ameaçadas" de dilaceramento a partir da emergência dos "outros" na contemporaneidade.

Essa menção aos "outros" nos leva ao conceito de alteridade com o qual operamos neste estudo. Conforme exemplificado acima, se tivermos em mente a marcação simbólica e social das identidades masculinas, digamos, dos homens brancos heterossexuais cristãos de origem anglo-saxã dos Estados Unidos, estabelecem-se como os "outros" - em oposição a essas referidas identidades - todas as demais subjetividades que se diferenciem dessas posições de sujeito. Nesse 
sentido, Michael Kimmel (2004) conclui que "conseguimos saber o que significa ser um homem em nossa cultura por meio do estabelecimento de nossas definições em oposição a um conjunto de 'outros' - minorias raciais, minorias sexuais e, acima de tudo, mulheres" (p. 182). ${ }^{3}$

A alteridade é, portanto, uma formulação essencial na elaboração e no estabelecimento simbólico e social da identidade de si e do outro (BOESCH, 2007), uma vez que, como observa Kathryn Woodward (2000), "a identidade é relacional e [...] marcada pela diferença" (p. 9). Gilbert Zouyané (2014) acrescenta que "consideramos que a alteridade [...] é consubstancial à identidade. [...] É com base na alteridade que se pode compreender e interpretar a coexistência de identidades diferenciadas em um dado espaço social" (p. 1). ${ }^{4}$ Retomando o exemplo da mulher, exemplificada acima por Kimmel (2004, p. 182) como a principal alteridade em relação à marcação identitária masculina, podemos afirmar que a categoria de "outro" é empregada conforme entendida por Simone de Beauvoir (1989). A partir de Emmanuel Lévinas, a autora argumenta que a ideia de "outridade" (ou "alteridade"), fundamental para o pensamento humano, não estava originalmente atrelada à divisão estanque entre os gêneros. Essa dualidade, tão primordial quanto a própria consciência, está relacionada, entretanto, ao fato de a Humanidade constituir-se predominantemente como masculina e definir as mulheres não em si mesmas, mas em relação ao homem. A partir desse estabelecimento do homem como sujeito, o feminino é reificado, relegado a uma posição secundária (o "outro"), estando fadado a contemplar o indivíduo masculino como o Absoluto e o Essencial (BEAUVOIR, 1989, p. xxii-xxiii). Além da mulher, as alteridades, em relação ao homem branco heterossexual, também podem ser atribuídas a diversos grupos minoritários (KIMMEL, 2004, p. 182).

Feitas essas breves delimitações dos termos-chave da presente investigação, passaremos, no que se segue, a analisar o conto "Catedral", de Raymond Carver, que, como mencionado anteriormente, coloca em questão, pela perspectiva da ameaça de fragilização e de fratura, as identidades de gênero e de raça no mundo pós-moderno.

\section{PoDe PORVENTURA UM CEGO GUIAR OUTRO CEGO?}

Antes de consolidar-se como um artista de reconhecida relevância no cenário literário dos Estados Unidos, o escritor Raymond Carver 
(1938-1988) passou a maior parte de sua vida imerso em adversidades (NESSET, 1995). Apesar de o autor ter vivido uma vida relativamente curta e bastante turbulenta, marcada por empregos insatisfatórios, um casamento infeliz, um grave problema com o alcoolismo e uma luta intensa contra o câncer, Carver produziu vários contos que foram reunidos em coletâneas como Will you please be quiet, please? (1976), What we talk about when we talk about love (1981) e Cathedral (1983) (BETHEA, 2001, p. 1-6; BLOOM, 2002, p.12-13,79). Carver ficou conhecido internacionalmente por suas histórias minimalistas ${ }^{5}$ e redigidas em linguagem simples, o que levou críticos como Harold Bloom, Frank Kermode, John Barth, entre outros, a compararem seu trabalho aos de Ernest Hemingway (BARTH, 1995, p. 69; BLOOM, 2002, p.12-13; JAMESON, 2015, p. 208) e de Anton Tchekhov (NESSET, 1995; KERMODE, 2000, p. 2; CLARK, 2015, p. 49-68). Os textos de Carver, sobretudo seus contos, representam por meio de sua prosa límpida uma América sem glamour, povoada por trabalhadores desencantados, personagens de certa forma embrutecidas pela aridez de suas experiências, cujas vidas banais se entrecruzam de maneira casual em um contexto de grande tensão (GRAY, 2011, p. 327; JAMESON, 2015, p. 205-220).

Em recente trabalho, Fredric Jameson tenta avaliar o caráter distintivo da obra de Carver e como esta tende a projetar um tipo específico de sujeito, fortemente calcado em sua própria biografia:

Desde sua morte em 1988, Raymond Carver tornou-se um dos escritores individualmente mais importantes do panteão da ficção americana contemporânea; e seus contos (ele nunca escreveu um romance) certamente projetam um universo distintivo a ponto de livros fotográficos terem sido publicados com o intuito de ilustrar o que chamam de "Carver country", que é associado com o noroeste dos Estados Unidos. Ao mesmo tempo, sua vida - pobreza, alcoolismo, sucesso tardio, sua musa - tornou-se algo lendário (JAMESON, 2015, p. 207-208). ${ }^{6}$

Em geral, esses seres ficcionais do sexo masculino projetados pelos contos do escritor sofrem profundas crises identitárias, como as representadas em filmes americanos adaptados a partir de narrativas de Carver como Short Cuts: cenas da vida (1993), de Robert Altman, 
Pronto para recomeçar (2010), de Dan Rush, e, sobretudo, Birdman ou a inesperada virtude da ignorância (2014), de Alejandro González Iñárritu.

Nesses filmes e, sobretudo, nas histórias de Carver que lhes serviram de base e de inspiração, deparamo-nos com homens brancos americanos comuns, irritados com seus relacionamentos e com seus cotidianos fracassados, ameaçados pelas condições econômicas desfavoráveis e cada vez mais intimidados pelas ondas multiculturalistas que fazem dos Estados Unidos um país tão diverso. Confrontadas com a gradativa erosão de sua hegemonia racial e de gênero e, especialmente, a perda do controle tradicionalmente exercido sobre as condições econômicas, essas personagens têm ímpetos de agressividade - como, por exemplo, em "Tell the women we're going" (1981), "So much water so close to home" (1981), "What we talk about when we talk about love" (1981), "A small, good thing" (1983) - ou ficam paralisadas pelo medo e pelo comodismo, como em "Night school" (1976), "Preservation" (1983) e no poema "Fear" (1985).

O narrador de "Catedral", último conto da coletânea Cathedral (1983), de Carver, é um sujeito dotado de todas essas características distintivas do universo ficcional do escritor: homem americano branco de meia-idade, insatisfeito com o emprego e com a domesticidade de sua vida, e em constante conflito conjugal. Por ser tão recorrente em textos do autor, esse tipo de personagem central quase invariavelmente não é nomeado nas histórias.

Em "Catedral", esse típico herói problemático, que é narrador em primeira pessoa, conta sobre a visita de um homem cego à sua casa. $\mathrm{O}$ visitante chama-se Robert e é um antigo amigo de sua esposa. Há dez anos ela havia trabalhado para Robert, fazendo-lhe leituras e organizando seu escritório. Anos mais tarde, a mulher do narrador deixa de trabalhar com Robert para se casar, porém, o casamento não é bemsucedido; ela divorcia-se do primeiro marido e, no momento presente, está casada com o narrador do conto. Quando a esposa do narrador deixa de trabalhar para Robert, este contrata uma nova secretária (Beulah) com quem vem a se casar posteriormente. Entretanto, depois de oito anos juntos, Beulah é diagnosticada com câncer e falece. Por todas essas razões, o narrador sente-se enciumado e, ao mesmo tempo, incomodado com a presença do cego em sua casa. Ao contrário do 
esperado, no entanto, a visita ocorre sem grandes incidentes. Após o jantar e vários drinques, o anfitrião convida Robert para fumar maconha. A mulher do narrador adormece no sofá, e os dois homens assistem a um documentário sobre catedrais europeias na televisão. Ainda sob o efeito da droga, o narrador pergunta ao homem cego se ele tem noção de como é a aparência de uma catedral. Robert responde que tem uma vaga ideia e então pede a ele que desenhe uma dessas edificações sacras sobre uma folha de papel. Robert segura a mão do narrador e ambos desenham uma catedral juntos, tateando de olhos fechados as marcas deixadas pela caneta sobre o papel. O narrador passa então a se sentir de uma maneira diferente.

O narrador de "Catedral" é um homem cheio de preconceitos em relação às pessoas com necessidades especiais e aos não brancos. Como uma representação ficcional do típico homem branco heterossexual americano, o narrador tem uma visão distorcida em relação às identidades não hegemônicas (mulheres, negros, pessoas portadoras de deficiências, minorias sexuais, entre outros). Nesse sentido, a personagem de Carver aproxima-se do diagnóstico de Kimmel (2013) quanto a esse perfil de sujeito: "[essa formação identitária do homem branco] tem que ver com o fato de que se sentir qualificado ou abalizado pela raça ou pelo gênero distorce sua visão" (p. xii). ${ }^{7}$

No início do conto, o narrador revela que "a visita dele não [lhe] deixou nem um pouco entusiasmado" $(622),{ }^{8}$ pois a cegueira de Robert era um fator que lhe causava incômodo: "Não era nem de longe um conhecido meu. E o fato de [Robert] ser cego me incomodava. [...] Um cego na minha casa não era uma coisa que eu pudesse aguardar com grande expectativa" (622, grifos nossos). Justamente por ter essa visão distorcida do "outro", o narrador - ilusoriamente sentindo-se autorizado ou balizado por seu gênero e raça privilegiados - enxerga a diferença como sinônimo de inferioridade. Para ele, Robert, por ser um portador de necessidades especiais, não é normal, isto é, trata-se de um "outro", um "estranho", uma espécie de alteridade ameaçadora prestes a "invadir" seu lar, sua base de centralização como sujeito.

Todas essas questões identitárias do conto estão envolvidas nessa resistência do eu-narrador ao contato com o "outro" e nesse receio de incluir Robert em seu círculo de convivência. Podemos ver, representada ficcionalmente no texto literário, como "a diferença é 
sustentada pela exclusão" (WOODWARD, 2000, p. 12), uma vez que a marcação simbólica da identidade desse eu-narrador em primeira pessoa constitui-se a partir da desvalorização da alteridade. Em outras palavras, essa dupla prática de significação do eu (como sendo balizado, autorizado ou "no direito" de se sentir superior) e do "outro" (como uma representação simbólica de inferioridade) fornece as bases para 0 posicionamento do narrador como sujeito. Woodward (2000) sintetiza esse duplo movimento da seguinte maneira:

A representação inclui as práticas de significação e os sistemas simbólicos por meio dos quais os significados são produzidos, posicionando-nos como sujeito. É por meio dos significados produzidos pelas representações que damos sentido à nossa experiência e àquilo que somos (WOODWARD, 2000, p.17).

Esse impulso de exclusão da diferença se manifesta no texto em várias passagens, especialmente no momento em que o narrador recorre ao senso comum e a simbolismos simplificadores do "outro" para tentar defini-lo ou categorizá-lo como diferente. O narrador afirma que o único contato que já tivera com deficientes visuais fora de modo indireto, por meio de estereótipos projetados por imagens cinematográficas: "A ideia que eu tinha de cegueira vinha do cinema, cegos se movimentavam devagar e nunca riam. Às vezes eram conduzidos por cães-guia" (622). Ao reduzir Robert a um mero estereótipo, o narrador tenta desumanizálo ou, pelo menos, inferiorizá-lo, objetificando-o sistematicamente. Como podemos perceber, uma das maneiras mais comuns de se marcar simbolicamente a identidade é por meio da estereotipagem da diferença, em geral, com a finalidade de desvalorizar ou objetificar o "outro":

Um estereótipo é uma forma como o eu reduz o outro a um objeto. Ao se olhar para os outros de uma maneira unidimensional, o eu pode sobreviver a qualquer ameaça que se possa imaginar à sua identidade ou lidar com o sentimento desconfortável de contato com o desconhecido ou com o não familiar (KEANE, 1999, p. 70). ${ }^{9}$

Além de desumanizar Robert, o narrador, que considera o cego como sendo menos homem do que ele, prossegue estereotipando sarcasticamente atributos e pessoas vinculadas a seu visitante. Essa 
atitude fica evidente na passagem em que o narrador demonstra, em um diálogo tenso com sua mulher, preconceitos de gênero e de raça em relação à falecida esposa de Robert, a quem chama de "o raio da mulher" (625):

Ela me falou um pouco mais sobre a mulher do cego. O nome dela era Beulah. Beulah! Isso é nome de mulher de cor.

"A mulher dele era crioula?", perguntei.

"Você está maluco?", disse minha mulher. "Será que você pirou de vez? [...] O que é que você tem?", perguntou. "Está embriagado ou o quê?"” (625).

O marido infere que um nome como Beulah naturalmente deve identificar uma mulher negra. Embora o texto não corrobore essa hipótese, seu comentário demonstra que ele tem noções simplistas, cristalizadas e essencialistas quanto à formação identitária das pessoas afrodescendentes. Porém, como mostra Stuart Hall (1987) em uma passagem bastante conhecida, isso é um equívoco, uma vez que a constituição das chamadas identidades negras deve ser desnaturalizada, pois se trata de um processo problemático e carregado de nuances:

Constituir-se como "negro" é um outro reconhecimento do eu por meio da diferença: certas polaridades inequívocas e extremidades em relação às quais tenta-se definir-se. [...] Por muito tempo se pensou que este é um processo bem simples: um reconhecimento - uma resolução de irresoluções, um repousar em algum lugar que sempre esteve lá esperando por si. O "verdadeiro eu", até que enfim! $\mathrm{O}$ fato é que [a identidade] "negra" nunca se encontrou lá. Ela tem sido sempre uma identidade instável em termos psíquicos, culturais e políticos. Ela também é uma narrativa, uma estória, uma história. Algo construído, contado, verbalizado, mas nunca simplesmente encontrado. [...] O negro é uma identidade que teve de ser aprendida [...] em um dado momento. [...] Então, a noção de que a identidade é uma simples questão - se me permitem a metáfora - de preto no branco, nunca foi essa a experiência das pessoas negras (HALL, 1987, p. 45). ${ }^{10}$

Em sua concepção estereotipada a respeito de raça e de gênero, o narrador menospreza a relação de amor entre Robert e Beulah, pois crê 
que a cegueira seja um empecilho para a felicidade plena de um casal, uma vez que, sendo cego, Robert seria não apenas um amante inferior, mas também menos homem do que o normal:

[Robert e Beulah] Casaram, moravam e trabalhavam juntos, dormiam juntos - faziam sexo, claro - e depois o cego teve de enterrar a mulher. Tudo isso sem ele jamais ter visto que aspecto tinha $o$ raio da mulher. Era uma coisa além da minha compreensão. Ao ouvir aquilo, tive um pouquinho de pena do cego. Depois me vi pensando na vida lamentável que aquela mulher devia ter tido. Imagine uma mulher que nunca podia se ver como era vista pelos olhos do homem que amava. Uma mulher que vivia dia após dia sem nunca receber um elogio do seu amado. Uma mulher cujo marido nunca ia poder ver a expressão do rosto dela, fosse de angústia ou de alguma coisa melhor. Alguém que podia usar maquiagem ou não usar - que diferença faria para ele? Se quisesse, ela poderia usar uma sombra verde em volta de um olho, um alfinete enfiado no nariz, calças amarelas folgadas e sapatos roxos, tanto fazia. [...] [E]le nunca soube como era o aspecto dela de verdade, e lá ia a mulher num trem expresso direto para a sepultura (625-626, grifos nossos).

Entretanto, com a chegada de Robert, o narrador começa a perceber que suas concepções sobre os deficientes visuais estão equivocadas, pois, além de rir alto e de se mover com desenvoltura, ele "não usava bengala nem óculos escuros. Sempre pensei que óculos escuros fossem uma obrigação para os cegos" (627). Alguns desses comentários politicamente incorretos são verbalizados pelo narrador, causando, com isso, a irritação de sua esposa, cuja postura é de muito mais tolerância com as diferenças. Um pouco antes de Robert chegar, por exemplo, há uma sequência narrativa carregada de tensão entre o narrador e sua esposa por causa da forma sarcástica como ele insiste em antagonizar esse "outro" que ele nem mesmo conhece.

Outro fator que também colabora para gerar a tensão quanto à possível reação negativa do narrador, quando este se encontrar com Robert, está relacionado ao ciúme daquele por sua esposa. O narrador mantém uma postura hostil em relação aos homens que passaram pela vida de sua mulher. Ele refere-se ao ex-marido militar de sua esposa como "o tal homem que foi o primeiro a desfrutar os favores dela" 
(623) e, enciumado, promove um apagamento da identidade do oficial do exército: "por que ele precisaria ter um nome?" (624). Contudo, ele parece ter ainda mais ciúme de Robert, pois, no último dia em que a esposa do narrador trabalhou para ele, o homem cego "perguntou se podia tocar no rosto dela. Minha mulher concordou. Contou que os dedos dele tocaram em todas as partes do seu rosto, o nariz - até o pescoço! Ela nunca esqueceu. Tentou até escrever um poema sobre isso" (623).

Dessa forma, podemos notar que Robert representa uma ameaça para o narrador e isso é a causa maior de seu desconforto em relação à visita, pois, ao contrário do marido, o homem cego é uma pessoa afável e intrigante: "muito do ciúme do primeiro marido sofre transferência para o cego Robert. Assim, Robert ameaça o narrador sexualmente com sua cegueira e devido ao fato de ele representar um passado que é significativo para a esposa" (FACKNITZ, 1986, p. 293, grifos nossos). ${ }^{11} \mathrm{~A}$ reação intensa do narrador ao pedido do cego pode ser interpretada como se ele, em um nível inconsciente, sentisse como se Robert houvesse "penetrado" sua esposa, pois parece perceber carga sexual no ato praticado pelo cego e um certo simbolismo fálico em seus dedos. Nesse sentido, Mark Facknitz observa que: "Claramente ele sente ciúme, e, portanto, enfatiza o erotismo do toque do homem cego" (1986, p. 293). ${ }^{12}$

Com a proximidade da visita de Robert, o narrador, sentindo-se contrariado pelo fato de sua esposa ter um amigo íntimo do sexo oposto e confrontado com a possibilidade de ter de compartilhar seu espaço com esse "outro" ameaçador, é tomado por uma espécie de ansiedade irracional. O caráter da marcação simbólica identitária demonstrado pelo narrador remete ao chamado comportamento homossocial. A partir de Jean Lipman-Blumen (1976), Kimmel e Aronson (2004) observam que a homossociabilidade

é a orientação mútua de membros do mesmo sexo e é "a busca, o deleite, e/ou a preferência pela companhia do mesmo sexo" [...]. Em cenários homossociais, os homens determinam mutuamente o que faz um homem (normal). [...] Entre adultos do sexo masculino, [...] ser validado por outros homens confirma a masculinidade do homem. [...] Há duas características interconectadas dos contextos 
homossociais sobre as quais a identidade masculina é fundada: a diferença em relação ao universo das mulheres, que é frequentemente desvalorizado, e a conjunção com outros homens. [...] A cultura interacional de grupos homossociais masculinos apresenta uma enorme variedade. [...] O grupo homossocial deve ser visto como um "ator coletivo" na construção da diferença e da masculinidade hegemônica (KIMMEL; ARONSON, 2004, p. 396-397). ${ }^{13}$

Como sugerem os pesquisadores, essa copresença de homens em ambientes e situações em que performatizam suas masculinidades por meio de comportamentos homossociais serve, em grande medida, para marcar simbólica e tacitamente os contornos e limites da identidade de gênero. Para esses sujeitos masculinos, essas ocasiões de homossociabilidade, apesar de algumas vezes serem gratificantes, são cercadas de medos irracionais e de ansiedades inconscientes, pois os participantes sabem que suas performances de gênero serão mutuamente monitoradas através do olhar do(s) outro(s) homem(ns), como atesta Kimmel (2004):

O pai é o primeiro homem que avalia a performance masculina do menino, o primeiro par de olhos machos diante dos quais o garoto tenta provar a si mesmo. Esses olhos o seguirão pelo resto de sua vida. Os olhos de outros homens se juntarão a eles - os olhos dos homens que lhe servem de modelo, tais como professores, treinadores, patrões ou heróis da mídia; os olhos de seus pares, de seus amigos, de seus colegas de trabalho; e os olhos de milhões de outros homens, vivos ou mortos, de cujo escrutínio constante de sua performance ele nunca estará livre (KIMMEL, 2004, p. 188). ${ }^{14}$

Esse escrutínio permanente visa à exclusão das diferenças isto é, à supressão de traços estigmatizados pertencentes a "outros" como mulheres, minorias raciais, sexuais, e assim por diante - e pode incluir, além da misoginia e do racismo, a homofobia como um importante componente na marcação simbólica da diferença. Kimmel (2004) entende a homofobia como um conceito operacional bastante significativo nessas interações masculinas. Para o autor, "a homofobia é o medo de que os outros homens nos desmascarem, nos emasculem, e de que revelem para nós mesmos e para o mundo que nós não estamos 
à altura, que nós não somos homens de verdade" (KIMMEL, 2004, p. 189). ${ }^{15}$

Como já mencionado, a personalidade do narrador está intimamente ligada a formulações da identidade masculina do americano a partir de comportamentos homossociais. Dessa maneira, parte da ansiedade do narrador em relação à presença do visitante cego pode ser compreendida com base nos fatos de Robert ser, segundo ele, anormal, ser (de certa forma) menos homem, ter sido casado com uma negra e não enxergar: "E o fato de [ele] ser cego me incomodava" (622, grifos nossos).

Dadas essas motivações, o narrador manifesta seu incômodo em relação à visita de Robert sob a forma de uma série de discriminações: primeiro, ele zomba de sua cegueira, atribuindo-lhe adjetivos como "incômodo" (622) e "sinistro" (627); depois, critica o fato de sua esposa ter tido uma "vida lamentável" por nunca ter sido vista por ele (625), e, por fim, classifica como "patético" (626) o modo como o cego despedese de sua esposa durante o funeral.

Essas atitudes de intolerância e de discriminação em relação ao "outro" podem ser interpretadas como uma espécie de projeção psicológica (cf. KLEIN; RIVIERE, 1964, p. 11-12) mobilizada pelo eu (no caso, o narrador em primeira pessoa) como mecanismo de defesa contra seus próprios sentimentos íntimos de medo e de vulnerabilidade. ${ }^{16}$ O narrador de "Catedral" demonstra, em várias instâncias, que se sente intimidado (e inconscientemente emasculado) pelo fato de Robert ser um "verdadeiro homem dos sete instrumentos" (629) ao passo em que ele tem múltiplas vulnerabilidades. Por não saber lidar com essas emoções desconfortáveis em sua própria mente, projeta-as para fora de si, automaticamente atribuindo-as ao "outro". Melanie Klein e Joan Riviere (1964, p. 11) observam que, como é típico nesse mecanismo psicológico, "todos os sentimentos [...] dolorosos ou desagradáveis na mente são, por meio desse mecanismo, automaticamente relegados para fora do eu. [...] Nós os negamos e repudiamos como procedentes de nós mesmos; [...] [e] passamos a culpa por eles adiante, para um outro alguém". ${ }^{17}$

E o "outro" em questão, em comparação com o eu-narrador, apresenta inúmeros atributos. Conforme o texto indica, Robert, esse "cego que era um verdadeiro homem dos sete instrumentos" (629), 
mantém um pequeno escritório no departamento municipal de serviço social (623), o que denota sua preocupação com o bem-estar das pessoas de sua comunidade e seus esforços no sentido de ajudá-las. Além disso, o cego tem uma ótima capacidade de criar vínculos com outras pessoas, o que é sugerido por suas atividades como operador de radioamador: "Com aquela sua voz retumbante, [Robert] falava de suas conversas com radioamadores em Guam, nas Filipinas, no Alasca e até no Taiti. Disse que teria uma porção de amigos à disposição se algum dia quisesse visitar aqueles lugares" (629, grifo nosso). O narrador, por outro lado, prefere a comunicação unilateral do velho aparelho de televisão, enquanto o visitante interage com seus amigos por diferentes meios (interações por cartas, fitas cassete, radioamador, entre outros). Além de não ter "amigo nenhum" (625), o narrador também é um homem frustrado em relação ao seu trabalho, mas, como suas respostas lacônicas às indagações de Robert mostram (629), ele se sente impotente para superar sua própria insatisfação. Em outras palavras, os ataques do eu ao "outro" tentam mascarar o fato de que o narrador parece sentir sua própria identidade hegemônica fraquejar diante da ameaça simbólica da alteridade e de fatores profissionais e pessoais desfavoráveis que contribuem para enfraquecê-la ou fluidificá-la.

Em oposição ao narrador, que culpa o "outro" por suas próprias fragilidades e tem uma intolerância arraigada em sua mente - conforme sugere seu apego ao velho sofá (626), ou seja, uma metáfora do comodismo e das ideias antiquadas que ele concebe -, a afabilidade de Robert está relacionada à sua receptividade a novas experiências. Em lugar de rejeitar a oferta de maconha, pois o homem cego jamais experimentara a droga antes, Robert aceita consumi-la sem a menor hesitação. Segundo ele, "o aprendizado nunca termina" (632). E a habilidade do visitante em aprender coisas novas é notável, pois o narrador comenta que Robert aprendeu a fumar maconha imediatamente: "Parecia que fazia aquilo desde o[s] nove anos" (631). A capacidade de aprendizagem do narrador, por outro lado, é bem mais limitada: ele se diz incapaz de entender e de interagir com a poesia (623), sofre com pesadelos recorrentes que não compreende (632) e tem dificuldades em manter um diálogo produtivo com sua esposa (625). Podemos inferir que é ele, na verdade, quem sofre (simbolicamente) de cegueira, pois se recusa a ver a vida com mais "poeticidade", a manter-se aberto a novas 
experiências e, acima de tudo, parece não compreender a diferença entre enxergar e ver.

Contrariando as expectativas do leitor, desencadeadas pelo suspense gerado durante o desenvolvimento do enredo, a visita de Robert ocorre sem problemas, mesmo quando a esposa se ausenta momentaneamente ou adormece. A tensão homossocial arrefece quando o narrador faz a proposta de consumo de maconha. Na verdade, o anfitrião tenta demonstrar superioridade em relação ao cego ao oferecer a droga, pois presume que ele, por ser cego e "frágil", não a aceitaria. Sua tática, no entanto, não prospera. O consumo compartilhado da droga atua no sentido de desfazer, no ânimo do narrador, as assimetrias homossociais e instaurar, ainda que momentaneamente, uma trégua no duelo de masculinidades entre o eu e o "outro".

Além disso, o narrador se dá conta de que seu antagonismo em relação ao escrutínio de sua performance como homem através dos olhos do "outro" não faz sentido, uma vez que, sendo cego, Robert não representa esse tipo de vigilância. O narrador observa que o visitante, por exemplo, nem percebe que a anfitriã, adormecida, deixa a coxa à mostra:

A cabeça dela estava tombada para trás, sobre o encosto do sofá, e ela estava de boca aberta. Tinha virado de um jeito que o roupão havia escorregado de suas pernas, deixando à mostra uma coxa bem suculenta. Estiquei a mão para puxar o roupão por cima dela e aí lancei um olhar para o cego. Que diabo! Larguei a aba do roupão aberta outra vez (632, grifos nossos).

O narrador percebe, aliviado momentaneamente da ansiedade homossocial, que, "Robert não o ameaça com sua cegueira e não pode desmascará-lo com sua visão" (BENSON, 2009, p. 92). ${ }^{18}$ Por não ver mais o cego como uma ameaça sexual em relação à sua mulher, o narrador - tendo por ora aplacado suas inseguranças e ansiedades - sente liberdade para se conectar com o "outro". Nesse sentido, observa Kevin Keane (1999) que "é difícil sentir qualquer tipo de vergonha quando ninguém pode vê-lo, então a presença de Robert dá a ele uma sensação de liberdade que ele não sentia no mundo dos que veem" (p. 72). ${ }^{19}$ 
Temporariamente livre das inseguranças impostas pelo antagonismo homossocial em relação a Robert, proporcionado, em grande medida, pelo consumo de grandes quantidades de álcool e da substância psicoativa, o narrador consegue superar sua fobia dos dedos "fálicos" do cego, deixando-se "penetrar" pela afetividade do "outro". A atividade homoafetiva de desenhar uma catedral juntos - a mão da personagem cega guiando a mão do narrador - estabelece um vínculo de intimidade entre ambos: "Estamos desenhando uma catedral. Eu e ele estamos fazendo esse trabalho" (636), diz Robert à esposa do narrador. E, em seguida, o visitante lembra ao anfitrião a importância desse tipo de socialização: "Vamos pôr umas pessoas lá dentro agora. O que é uma catedral sem gente?" (637).

Ao sentir-se temporariamente privado de sua visão, pois Robert pedira-lhe que desenhasse de olhos fechados (637), o narrador sentese na posição do "outro" e, dessa forma, experimenta uma epifania (cf. BECKSON; GANZ, 1989; SOBREIRA, 2013). Repentinamente, há uma iluminação súbita na consciência do narrador, uma percepção reveladora de uma determinada realidade, a partir da qual ele se liberta, ainda que momentaneamente, de seu isolamento, de seu egocentrismo, e passa a perceber sua própria realidade de uma maneira nova: “É mesmo incrível', falei" (637). Assim como ocorrera com a esposa do narrador que, após ser tocada por Robert, sente um toque de poesia, o anfitrião, ao ser tocado pelos dedos do cego, também vivencia uma emoção quase poética. Ou seja, ele deixa de simplesmente enxergar e passa a ver.

Essa experiência epifânica de aguçamento da percepção pode ser observada na passagem final, em que o narrador tenta descrever as sensações de liberdade e de leveza: "Meus olhos ainda estavam fechados. Eu estava na minha casa. Sabia disso. Mas não tinha a sensação de estar dentro de nada" (637). Ao sentir-se por alguns momentos desprendido de seu próprio aprisionamento, finalmente vendo em vez de só enxergar, o narrador toma consciência do significado de algo que é muito maior do que ele mesmo, do que sua casa, do que seu mundo recluso, e passa a experimentar, ainda sob o efeito das drogas, uma liberdade extraordinária. A palavra utilizada por ele para descrever a sensação vivida - "É mesmo incrível" (637, grifo nosso) - revela seu êxtase e sua incapacidade de articular por meio da linguagem o significado dessa 
experiência, que é um divisor de águas em sua vida: "Nunca na vida eu tinha experimentado uma coisa assim" (637).

\section{CONSIDERAÇÕES FINAIS}

Assim como ocorre em outra narrativa de Carver ("A small, good thing"), a referência à simbologia cristã, evocada não apenas pelo título do conto "Catedral", mas também por discussões sobre o tema entre as personagens (632-637), permeia o texto como um todo. O narrador confessa não ser uma pessoa religiosa, porém, apesar disso, o símbolo cristão da catedral está vinculado à comunhão do eu com o "outro". É por meio da reconciliação do eu com o "outro" em torno de um projeto comum - o desenho de uma catedral - que os antagonismos identitários, ao menos por um breve período de tempo, podem ser negociados na narrativa de Carver.

Como fizemos questão de frisar ao longo da análise, trata-se de uma comunhão temporária, uma vez que seria estranho esperar que todos os antagonismos possam ser definitivamente apaziguados. Além disso, a superação duradoura de entraves emocionais não seria condizente com o estilo minimalista praticado pelo artista.

Por fim, precisamos nos deter sobre a importância simbólica da cegueira no conto "Catedral", de Raymond Carver. O texto opera com duas perspectivas diametralmente opostas desse aspecto: ser cego inicialmente simboliza "ignorar a realidade das coisas, negar as evidências e, portanto, ser louco, lunático, irresponsável”; por outro lado, o cego, como símbolo, também está vinculado "àquele que ignora as aparências enganosas do mundo e, graças a isso, tem o privilégio de conhecer sua realidade secreta, profunda, proibida aos mortais vulgares. Ele participa do divino, ele é o inspirado, o poeta, o visionário, o Vedor" (CHEVALIER; GHEERBRANT, 1982, p. 88). ${ }^{20}$

O conto de Carver, portanto, subverte a simbologia em torno da cegueira, pois Robert, percebido pelo narrador como o "outro", como um tolo patético e anormal, é quem, na verdade, consegue não apenas ver além do nível superficial da realidade, mas também tocar até a mais dura intolerância à diferença. $\mathrm{O}$ eu-narrador, temeroso diante da ameaça de ter sua identidade, como diria Bauman (2001, p. 98), "feita em 
pedaços" pelo contato com o "outro", é, na prática, o cego desorientado nos possíveis (des)caminhos identitários da contemporaneidade.

\title{
LITERARY REPRESENTATIONS OF IDENTITY AND DIFFERENCE CONCERNING BLINDNESS STEREOTYPES
}

\begin{abstract}
This study aims at analyzing fictive representations of identity interplays between self and otherness in a contemporary literary narrative. Such configurations of identities and differences have been analyzed by means of an interdisciplinary approach to the minimalist short story "Cathedral" (1983) by American author Raymond Carver. The literary text problematizes the stereotypes involving otherness in terms of race, gender and physical disabilities. In such a duel of masculine performances, the first-person narrator is forced to negotiate symbolically his own phobias and anxieties concerning the differences.
\end{abstract}

KeYwORDS: identity, otherness, Raymond Carver, subject, postmodernity.

\section{REPRESENTACIONES LITERARIAS DE LA IDENTIDAD Y DE DIFERENCIA CON RESPECTO A LOS ESTEREOTIPOS DE LA CEGUERA}

\section{RESUMEN}

En este artículo, analizamos las representaciones ficcionales de embates de identidades entre el yo y el otro en una narrativa literaria contemporánea. Esas configuraciones de las identidades y de las diferencias son analizadas según las teorías interdisciplinarias del cuento minimalista "Cathedral" (1983), del escritor estadounidense Raymond Carver. El texto literario problematiza la estereotipación de las diferencias por causa de la raza, del género y de las discapacidades físicas. En ese duelo de performances masculinas, el yo narrador del cuento se ve obligado a negociar simbólicamente sus propias fobias y ansiedades respecto a las diferencias.

Palabras ClaVE: identidad, alteridad, Raymond Carver, sujeto, posmodernidad. 


\section{Notas}

1. "postmodern theory abandons the rational and unified subject postulated by much modern theory in favour of a socially and linguistically decentred and fragmented subject" (BEST; KELLNER, 1991, p. 4-5). Salvo quando indicado nas Referências, todas as traduções livres utilizadas neste trabalho são de responsabilidade do autor.

2. "El sujeto reflexivo, centrado y unitario de las Kritiken de Kant y de las abstracciones de Max Weber habría sido reemplazado por un cambiante sujeto descentrado, difuso y fragmentario que se mueve en un espacio que ya no está socialmente estructurado de una manera binaria. Con ello, la cuestión de la constitución de identidades también fue replanteada" (RINCÓN, 1995, p. 111).

3. "We come to know what it means to be a man in our culture by setting our definitions in opposition to a set of 'others'-racial minorities, sexual minorities, and, above all, women" (KIMMEL, 2004, p. 182).

4. “nous considérons que l'altérité [...] est consubstantielle à l'identité. [...] C'est en s'appuyant sur l'altérité qu'on peut comprendre et interpréter la coexistence des identités différenciées dans un espace social précis"'(ZOUYANÉ, 2014, p. 1).

5. O termo minimalismo costuma ser aplicado às artes plásticas (cujos maiores expoentes seriam Frank Stella, Donald Judd, Sol LeWitt, Carl Andre, entre outros), à música (John Cage) e ao design (Mies van der Rohe) para identificar uma tendência geral à simplificação e à redução dos elementos constitutivos do objeto artístico a parâmetros mínimos. Outras características do minimalismo (ou Minimal Art), sobretudo em pintura, referem-se à composição de telas, esculturas e instalações a partir de formas geométricas básicas e imagens abstratas, cujo estilo tende a ser impessoal e repetitivo (KARMEL, 2004, p.90-101). O termo minimalismo tem sido também associado à literatura para designar, em especial, a produção de contos de autores como Raymond Carver, Jay McInerney, Tobias Wolff, Bobbie Ann Mason, Frederick Barthelme, entre outros (cf. BARTH, 1995). Algumas características frequentemente atribuídas ao minimalismo literário incluem a acentuada simplificação vocabular, a criação de frases concisas e impessoais, a eliminação de traços que possam sugerir sentimentalidade ou emoção, além da busca por um esvaziamento 
de possíveis sentidos poéticos ou metafóricos atribuídos à palavra (cf. JAMESON, 1991, p. 253; CALABRESE, 1999, p. 183-184; GREGSON, 2004, p.142; CLARK, 2015). O conto tem sido apontado como o gênero minimalista por excelência em virtude de sua propensão tanto à brevidade quanto à redução da totalidade de uma determinada experiência a fragmentos mínimos (GREGSON, 2004, p.142; JAMESON, 2015, p. 208, 219, 284-285, 291-292).

6. "[S]ince his death in 1988, Raymond Carver has become one of the single most important writers in the pantheon of contemporary American fiction; and his stories (he never wrote a novel) certainly project a distinctive world, to the point where picture books have been published purporting to illustrate what they call 'Carver Country', which is associated with the Northwest of the United States. At the same time his life - poverty, alcoholism, late success, the muse - has become something of a legend" (JAMESON, 2015, p. 207-208).

7. "It's about how feeling entitled by race or gender distorts one's vision" (KIMMEL, 2013, p. xii).

8. Todas as citações do conto "Catedral" são da mesma edição (CARVER, 2010) e serão dadas, doravante, apenas por parentético número de página.

9. "A stereotype is one way that the self reduces the other to an object. By looking at others in a one-dimensional way, one can survive any imagined threats to one's identity or deal with the uncomfortable feeling of encountering the unknown or unfamiliar"(KEANE, 1999, p. 70).

10. "Constituting oneself as 'black' is another recognition of self through difference: certain clear polarities and extremities against which one tries to define oneself. [...] It has long been thought that this is really a simple process: a recognition - a resolution of irresolutions, a coming to rest in some place which was always there waiting for one. The 'real me' at last! The fact is 'black' has never been just there either. It has always been an unstable identity, psychically, culturally and politically. It, too, is a narrative, a story, a history. Something constructed, told, spoken, not simply found. [...] Black is an identity which had to be learned [...] in a certain moment. [...] So the notion that identity is a simple - if I can use the metaphor - black or white question, has never been the experience of black people" (HALL, 1987, p. 45). 
11. "much of his jealousy toward the first husband transfers to the blind man Robert. Thus Robert sexually threatens the narrator, with his blindness, and by virtue of being a representative of a past that is meaningful to the wife" (FACKNITZ, 1986, p. 293).

12. "Clearly he is jealous, and so emphasizes the eroticism of the blind man's touch" (FACKNITZ, 1986, p. 293).

13. "is the mutual orientation to members of the same sex and 'the seeking, enjoyment, and/or preference for the company of the same sex' [...]. Within homosocial settings, men mutually determine what makes a (normal) man. [...] Among adult males, [...] being acknowledged by other men confirms a man's masculinity. [...] There are two interconnected features of homosocial settings on which masculine identity is founded: distinction from the world of females that is often devalued, and conjunction with other men. [...]The interactional culture of male homosocial groups shows a great variety. [...] The homosocial group is to be seen as a 'collective actor' in the construction of difference and of hegemonic masculinity" (KIMMEL; ARONSON, 2004, p. 396-397).

14. "the father is the first man who evaluates the boy's masculine performance, the first pair of male eyes before whom he tries to prove himself. Those eyes will follow him for the rest of his life. Other men's eyes will join them - the eyes of role models such as teachers, coaches, bosses, or media heroes; the eyes of his peers, his friends, his workmates; and the eyes of millions of other men, living and dead, from those constant scrutiny of his performance he will never be free" (KIMMEL, 2004, p. 189).

15. "Homophobia is the fear that other men will unmask us, emasculate us, reveal to us and the world that we do not measure up, that we are not real men" (KIMMEL, 2004, p. 189).

16. Tais medos podem estar relacionados com o conceito mais amplo de homofobia defendido por Kimmel (2004, p. 189), conforme transcrito acima. Embora nenhum dos homens seja identificado como homossexual, essa homofobia "lato sensu", para Kimmel, pode ser traduzida como o medo de um "outro" do mesmo sexo, e envolve um pavor inconsciente do desmascaramento das próprias impotências e fragilidades como homem ou até mesmo o temor inconsciente da emasculação (cf. KIMMEL; ARONSON, 2004, p. 389-392). 
17. "All painful and unpleasant [...] feelings in the mind are by this device automatically relegated outside oneself [...]. We disown and repudiate them as emanating from ourselves; [...] [and] we blame them on to someone else" (KLEIN; RIVIERE, 1964, p. 11).

18. "Robert is non-threatening in his blindness and cannot unmask the narrator with his gaze" (BENSON, 2009, p. 92).

19. "It's hard to feel any sense of shame when nobody can see you, so Robert's presence gives him a new sense of freedom that he didn't feel in the seeing world” (KEANE, 1999, p.72).

20. “ignorer la réalité des choses, nier l'évidence et donc être fou, lunatique, irresponsable. [...] celui qui ignore les apparences trompeuses du monde, grâce à quoi il a le privilège de connaître sa réalité secrète, profonde, interdite au commun des mortels. Il participe du divin, c'est l'inspiré, le poète, le thaumaturge, le Voyant" (CHEVALIER; GHEERBRANT, 1982, p. 88).

\section{REFERÊNCIAS}

BARTH, John. A few words about minimalism. In: . Further fridays: essays, lectures, and other nonfiction (1984-94). Boston: Little, Brown and Company, 1995. p. 64-74.

BAUMAN, Zygmunt. Modernidade líquida. Tradução Plínio Dentzien. Rio de Janeiro: Zahar, 2001.

BEAUVOIR, Simone de. The second sex. Trans. H. M. Parshley. New York: Vintage, 1989.

BECKSON, Karl; GANZ, Arthur. Literary terms: a dictionary. 3. ed. New York: Noonday, 1989.

BENSON, Josef. Masculinity as homosocial enactment in three stories by Raymond Carver. The Raymond Carver Review, n. 2, p. 81-95, 2009. Disponível em: https://goo.gl/qeD5fn. Acesso: 12 mar. 2018.

BEST, Steven; KELLNER, Douglas. Postmodern theory: critical interrogations. New York: Guilford, 1991.

BETHEA, Arthur F. Technique and sensibility in the fiction and poetry of Raymond Carver. New York: Routledge, 2001. 
BLOOM, Harold (Ed.). Raymond Carver: Bloom's major short story writers. Philadelphia: Chelsea House, 2002.

BOESCH, Ernst E. The enigmatic other. In: SIMÃO, Lívia Mathias; VALSINER, Jaan (Ed.). Otherness in question: labyrinths of the self. Charlotte, NC: Information Age, 2007. p. 3-9.

BYERS, Thomas B. The revenant. Revista de Letras, v. 51, n. 2, p. 9-27, 2011. Disponível em: <goo.gl/oc29VR>. Acesso: 12 mar. 2018.

CALABRESE, Omar. A idade neobarroca. Tradução Carmen de Carvalho e Artur Morão. Lisboa: Edições 70, 1999.

CARVER, Raymond. Catedral. In: . 68 contos de Raymond Carver. Tradução Rubens Figueiredo. São Paulo: Companhia das Letras, 2010, p. 622637. House, 1985.

. Where water comes together with other water. New York: Random . What we talk about when we talk about love. New York: Knopf, 1981. . Will you please be quiet, please? New York: McGraw-Hill, 1976.

CHEVALIER, Jean; GHEERBRANT, Alain. Dictionnaire des symboles: mythes, rêves, coutumes, gestes, formes, figures, couleurs, nombres. Paris: Jupiter, 1982.

CLARK, Robert C. A Chekhov-Hemingway amalgamation: Raymond Carver's Cathedral. In: . American literary minimalism. Tuscaloosa: The University of Alabama Press, 2015. p. 49-68. Disponível em: $<$ https://goo. gl/YCAZxm>. Acesso: 12 mar. 2018.

FACKNITZ, Mark A. R. 'The calm', 'A small, good thing', and 'Cathedral': Raymond Carver and the discovery of human worth. Studies in Short Fiction, v. 23, n. 3, p. 287-296, 1986.

GRAY, Richard. A brief history of American literature. Oxford: WileyBlackwell, 2011.

GREGSON, Ian. Postmodern literature. London: Arnold/Oxford, 2004.

HALL, Stuart. The question of cultural identity. In: ; HELD et al. (Eds.). Modernity and its futures. Cambridge: Polity, 1992. p.273-316. . Minimal selves. In: APPIGNANESI, Lisa (Ed.). The real me: postmodernism and the question of identity. London: The Institute of Contemporary Arts, 1987. p.44-46. 
HARVEY, David. Condição pós-moderna: uma pesquisa sobre as origens da mudança cultural. 22. ed. Tradução Adail Ubirajara Sobral e Maria Stela Gonçalves. São Paulo: Loyola, 2012.

JAMESON, Fredric. The ancients and the postmoderns: on the historicity of forms. New York: Verso, 2015.

. Postmodernism or, the cultural logic of late capitalism. Durham, NC: Duke University Press, 1991.

KARMEL, Pepe. The year of living minimally. Art in America, v. 92, n.11, p. 90-101,149, Dec. 2004. Disponível em: https://goo.gl/i7JFn8.Acesso: 12 mar. 2018.

KEANE, Kevin. Perceiving the other in Raymond Carver's Cathedral. 女子 大文学外国文学篇, v. 51, p.69-82, 1999. Disponível em: <https://goo.gl/ CJvcTD>. Acesso: 12 mar. 2018.

KERMODE, Frank. No tricks. London Review of Books, v. 22, n. 20, p. 1718, 2000. Disponível em: <http://www.lrb.co.uk/v22/n20/frank-kermode/notricks> Acesso em: 1 jul. 2003.

KIMMEL, Michael. Angry white men: American masculinity at the end of an era. New York: Nation Books, 2013.

. Masculinity as homophobia: fear, shame, and silence in the construction of gender identity. In: MURPHY, Peter F (Ed.). Feminism \& masculinities. Oxford: Oxford University Press, 2004, p.182-199.

; ARONSON, Amy. Men and masculinities: a social, cultural, and historical encyclopedia. Santa Barbara, CA: Abc-clio, 2004. v. I.

KLEIN, Melanie; RIVIERE, Joan. Love, hate and reparation. New York: W. W. Norton \& Company, 1964.

LIPMAN-BLUMEN, Jean. Toward a homosocial theory of sex roles: an explanation of the sex segregation of social institutions. Signs, n. 1, p. 15-31, 1976. Disponível em: <https://goo.gl/9D7eEG>. Acesso: 12 mar. 2018.

LYOTARD, Jean-François. O pós-moderno. Tradução Ricardo Corrêa Barbosa. 3.ed. Rio de Janeiro: José Olympio, 1988.

NESSET, Kirk. The stories of Raymond Carver: a critical study. Athens: Ohio University Press, 1995.

RINCÓN, Carlos. La no simultaneidad de lo simultáneo: postmodernidad, globalización y culturas en América Latina. 2. ed. Bogotá: Universidad Nacional, 1995. 
SOBREIRA, Ricardo. Et soudain tout est devenu clair pour lui: la prise de conscience exprimée par l'épiphanie littéraire. Tabuleiro de Letras, n. 7, p. 33-44, 2013. Disponível em: <https://goo.gl/EGqtF8>. Acesso: 12 mar. 2018.

WOODWARD, Kathryn. Identidade e diferença: uma introdução teórica e conceitual. In: SILVA, Tomaz Tadeu da. Identidade e diferença: a perspectiva dos estudos culturais. 4.ed. Petrópolis, RJ: Vozes, 2000, p. 7-72.

ZOUYANÉ, Gilbert (Ed.). Identité, altérité et représentations. Paris: L'Harmattan, 2014.

Submetido em 1 de setembro de 2017

Aceito em 5 de março de 2018

Publicado em 31 de agosto de 2018 